\title{
Misguidance and modulation of axonal regeneration by Stat3 and Rho/ROCK signaling in the transparent optic nerve
}

\author{
V Pernet ${ }^{\star, 1}$, S Joly ${ }^{1}$, N Jordi ${ }^{1}$, D Dalkara ${ }^{2}$, A Guzik-Kornacka ${ }^{1}$, JG Flannery ${ }^{3}$ and ME Schwab ${ }^{1}$
}

The use of the visual system played a major role in the elucidation of molecular mechanisms controlling axonal regeneration in the injured CNS after trauma. In this model, CNTF was shown to be the most potent known neurotrophic factor for axonal regeneration in the injured optic nerve. To clarify the role of the downstream growth regulator Stat3, we analyzed axonal regeneration and neuronal survival after an optic nerve crush in adult mice. The infection of retinal ganglion cells with adenoassociated virus serotype 2 (AAV2) containing wild-type (Stat3-wt) or constitutively active (Stat3-ca) Stat3 cDNA promoted axonal regeneration in the injured optic nerve. Axonal growth was analyzed in whole-mounted optic nerves in three dimensions (3D) after tissue clearing. Surprisingly, with AAV2.Stat3-ca stimulation, axons elongating beyond the lesion site displayed very irregular courses, including frequent $U$-turns, suggesting massive directionality and guidance problems. The pharmacological blockade of ROCK, a key signaling component for myelin-associated growth inhibitors, reduced axonal U-turns and potentiated AAV2.Stat3-ca-induced regeneration. Similar results were obtained after the sustained delivery of CNTF in the axotomized retina. These results show the important role of Stat3 in the activation of the neuronal growth program for regeneration, and they reveal that axonal misguidance is a key limiting factor that can affect long-distance regeneration and target interaction after trauma in the CNS. The correction of axonal misguidance was associated with improved long-distance axon regeneration in the injured adult CNS.

Cell Death and Disease (2013) 4, e734; doi:10.1038/cddis.2013.266; published online 18 July 2013

Subject Category: Neuroscience

The failure of adult CNS axons to regenerate is a crucial factor for permanent neurological deficits after large injuries. To study the mechanisms of axonal growth in the CNS, the optic nerve lesion model has been extensively used. The stimulation of the retinal ganglion cell (RGC) growth program by deleting growth repressors such as the transcription factor Krüppel-like factor 4 (KLF4) ${ }^{1}$ or the phosphatase and tensin homolog (PTEN) ${ }^{2}$ allowed the activation of long-distance axonal regeneration. Clinically more feasible is the delivery of ciliary neurotrophic factor (CNTF) mediated by adenoassociated virus (AAV) infection, which also strongly promoted the regeneration of optic nerve axons. ${ }^{3-5}$ In all these experiments, however, regeneration distances still remained limited in the optic nerve; very few axons grew past the optic chiasm, and they did so only in cases of the strongest growth activation. ${ }^{6}$ Retinal axon regeneration is usually shown by counting labeled fibers on optic nerve sections at defined distances past the lesion site. This simple evaluation does not yield any information on branching or on directionality changes and guidance of the regenerating axons. In the present study, we, therefore, used a three-dimensional (3D) reconstruction of fluorescently labeled axons in wholemounted, cleared optic nerves to determine the pattern of axonal regeneration, similarly to what has been done in the injured spinal cord. ${ }^{7,8}$

CNTF signals via the Jak/Stat3 pathway, and pharmacological blockers of the Jak/Stat3 signaling pathway indicated a central role for Stat3 in RGC regeneration. ${ }^{9,10}$ Nevertheless, the exact contribution of the important growth regulator Stat3 had not been directly addressed so far. Genetic ablation of the suppressor of cytokine signaling 3(SOCS3) in RGCs promoted axonal regeneration, but mostly in conjunction with cytokine/ CNTF signaling. ${ }^{11}$ Here, we analyzed whether the activation of Stat3 specifically in RGCs can promote axonal regeneration

\footnotetext{
${ }^{1}$ Brain Research Institute, University of Zürich and Department of Health Sciences and Technology, ETH Zürich, Winterthurerstrasse 190, Zürich, CH-8057 Switzerland; ${ }^{2}$ Department of Chemical Engineering, Department of Bioengineering and Helen Wills Neuroscience Institute, University of California at Berkeley, Berkeley, CA 94720 , USA and ${ }^{3}$ Department of Molecular and Cellular Biology and Helen Wills Neuroscience Institute, University of California at Berkeley, Berkeley, CA 94720, USA. ${ }^{*}$ Corresponding author: V Pernet, Brain Research Institute, University of Zürich and Department of Health Sciences and Technology, ETH Zürich, Winterthurerstrasse 190, Room Y55J34a, Zürich, CH-8057, Switzerland. Tel: + 414463532 56; Fax: + 414463533 03; E-mail: pernet@ hifo.uzh.ch Keywords: axonal regeneration; gene therapy; optic nerve; retinal ganglion cells; Stat3

Abbreviations: AAV2, adeno-associated virus serotype 2; AKT, protein kinase B; ATF3, activating transcription factor 3; CNTF, ciliary neurotrophic factor; CTb, cholera toxin beta subunit; ERK1/2, extracellular-signal regulated kinase 1/2; GAP-43, growth-associated protein 43; GAPDH, glyceraldehyde-3-phosphate dehydrogenase; GFP, green fluorescent protein; IRF1, interferon regulatory factor 1; JAK, Janus kinase; KLF4, Krüppel-like factor 4; LIF, leukemia inhibitory factor; NF $\kappa B$, nuclear factor kappa b; P21, cyclin-dependent kinase inhibitor 1 a; PBS, phosphate buffered saline; PIAS3, protein inhibitor of activated stat3; PTEN, phosphatase and tensin homolog; qRT-PCR, quantitative real-time polymerase chain reaction; RGCs, retinal ganglion cells; ROCK, rho-kinase; RPL19, ribosomal protein I19; ShH10, AAV6 parent serotype from shuffled (ShH) library; SOCS3, suppressor of cytokine signaling 3; SPRR1A, small proline-rich protein 1a; STAT3, signal transducer and activator of transcription 3

Received 15.5.13; revised 11.6.13; accepted 17.6.13; Edited by A Verkhratsky
} 
independently of cytokine activation by infecting RGCs with AAV2 containing the wild-type or constitutively active Stat3, in which case the mutations $\mathrm{A} 662 \mathrm{C}$ and N664C confer to Stat3 a conformation mimicking the active state resulting from Tyr705 phosphorylation. ${ }^{12}$ The AAV2 tropism has been previously shown to be specific to RGCs in the retina. ${ }^{13,14}$

In the present study, we found that Stat3-wt and Stat3-ca were sufficient to activate axonal regeneration after an optic nerve injury. However, a 3D analysis revealed that the course of growing axons stimulated by AAV2.Stat3-ca presented elevated proportions of U-turns. This directional defect of elongating axons could be corrected by blocking ROCK with the pharmacological agent Y27632, thereby mimicking the robust effects of CNTF on axonal regeneration. A surprising effect of Y27632 was the phosphorylation of Stat3-ca, which boosted the expression of downstream genes. Our results show for the first time how the behavior of single axons is modulated by the CNTF/Jak/Stat3 pathway. These findings may be used to improve long-distance axonal regeneration in the injured CNS and in glaucoma. ${ }^{15}$

\section{Results}

Retinal ganglion cell transduction with wild-type (wt) or constitutively active (ca) Stat3 is sufficient to activate growth gene expression and axonal regeneration in vivo. In order to determine the influence of Stat3 on neuronal survival and axonal regeneration in 2-month-old adult mice, RGCs were injured by an optic nerve crush 4 weeks after an intravitreal injection of recombinant AAV2 containing the mouse sequence of wild-type or constitutively active Stat3 cDNA. The transduction of RGCs with AAV2 vectors was checked using immunohistochemistry on retinal flat-mounts (Figures 1a, b) and using qRT-PCR ( $n=3$ mice/ group; Figure 1c). In the untreated intact retina, endogenously expressed Stat3 was very low, while retinae receiving AAV2.Stat3-ca injection showed many Stat3-positive cells corresponding to RGCs, as determined by the colocalization of the RGC marker $\beta 3$ Tubulin and the Stat3 signal (Figure 1b). Using qRT-PCR, AAV2.Stat3-wt and AAV2.Stat3-ca increased to a similar extent the level of Stat3 mRNA-4- to 6-fold in intact and 10- to 11-fold in injured retinae collected 5 days after the optic nerve crush. Strikingly, the transcript levels of Sprr1A and Gap-43, two proteins associated with the activation of the neuronal growth state, ${ }^{14,16,17}$ were very significantly elevated in AAV2.Stat3injected retinae compared with control samples infected with AAV2.GFP or those left untreated (Figure 1c). To our surprise, the expression of three other Stat3 target genesPias3, Socs3 and p21-was not significantly affected (Supplementary Figure S1). The levels of Socs3 and p21 mRNA were upregulated by an optic nerve crush but not by Stat3 overexpression (Supplementary Figures S1c, d).

The axonal regeneration was then assessed 2 weeks after the optic nerve crush and anterograde tracing with cholera toxin $\beta$ subunit coupled to alexa-594 (CTb-594). On longitudinal optic nerve sections, more growing axonal fibers were observed beyond the lesion site in mice administered with AAV2.Stat3-ca ( $n=6$ mice Figures 1d, e) or AAV2.Stat3-wt
( $n=5$ mice) than in AAV2.GFP-injected or uninjected control animals ( $n=8$ mice; Figures 1f, g). Quantitatively, AAV2.Stat3-ca and AAV2.Stat3-wt caused significantly more fibers to grow up to $700 \mu \mathrm{m}$ and $500 \mu \mathrm{m}$, respectively, past the lesion site than did the AAV2.GFP virus delivery (Figure 1h). The effects of Stat3-wt and Stat3-ca transgenes on axonal regeneration were remarkably similar and consistent with the expression pattern of growth genes detected using qRT-PCR. We also counted the surviving $\beta 3$-tubulin-stained RGCs in the same groups: their density was not increased by Stat3-ca (Figures $1 \mathrm{i}$ and $\mathrm{j}$ ). Together, these results show that intracellular activation of Stat3 enhances axonal regeneration but has no neuroprotective effects.

Three-dimensional analysis of axonal regeneration in the whole-mounted optic nerve reveals directional and guidance errors. To better characterize the behavior of regenerating axons after injury, complete unsectioned optic nerves were cleared (see methods) after anterograde tracing with CTb-594 and reconstructed from stacks of confocal micrographs in 3D. As shown in videos and top- and sideview snapshots, axons could be visualized in the full depths of whole transparent optic nerves (Video 1, 2; Figures 2a-d, g-j). The courses of some of the longest axons labeled with CTb-594 in each nerve were traced and are shown as 2D projections (Figures 2e, f, k, I). In untreated mice, the few spontaneously growing axons occurred within a range of $500 \mu \mathrm{m}$ distal to the injury site (Figures $2 \mathrm{a}, \mathrm{b}, \mathrm{m}$ ). None of the axons showed the typical straight course of intact fibers parallel to the long axis of the nerve. Rather, axons followed oblique angles, turned at right angles, or showed U-turns, continuing their course back toward the lesion site (Figures 2c-f). AAV2.Stat3-ca-injected mice showed a higher density of axons, extending up to $1000 \mu \mathrm{m}$ away from the site of the crush (Figures 2g, h). Again, their course was very irregular, and at the regeneration front, many of the axons showed $\mathrm{U}$-turns or turns at right angles (Figures $2 \mathrm{i}-\mathrm{l}$ ). Some of these axons could be followed for several hundreds of micrometers on their way back toward the lesion. Repetitive turns were also seen. Quantitatively, the number of axonal fibers growing at 500,800 , and $1000 \mu \mathrm{m}$ after the injury was much higher with AAV2.Stat3-ca ( $n=5$ mice) than in the untreated or AAV2.GFP-injected mice ( $n=8$ mice; Figure $2 \mathrm{~m}$ ). As an indicator of the growth range, the distances from the lesion site of the 20 longest axons were estimated; this index showed that the axons were able to grow farther in the damaged optic nerve with AAV2.Stat3-ca stimulation than in control conditions (Figure 2n). The number of growing fibers (measured at $500 \mu \mathrm{m}$ ) in the whole cleared optic nerve was equivalent to that determined on a series of tissue sections, suggesting that CTb-594 tracing is not altered by the organic solvents used during the clearing procedure (compare with Figure 1h). Interestingly, the proportion of axonal U-turns was more than doubled to over $40 \%$ of the axons when regeneration was activated by Stat3-ca transfection, compared with control mice (Figure 20). The whole-mount $3 \mathrm{D}$ analysis method used here reveals that Stat3-mediated axonal regeneration is characterized by irregular axonal trajectories and U-turns that most likely reflect the influence of inhibitory molecules in the optic nerve environment. 

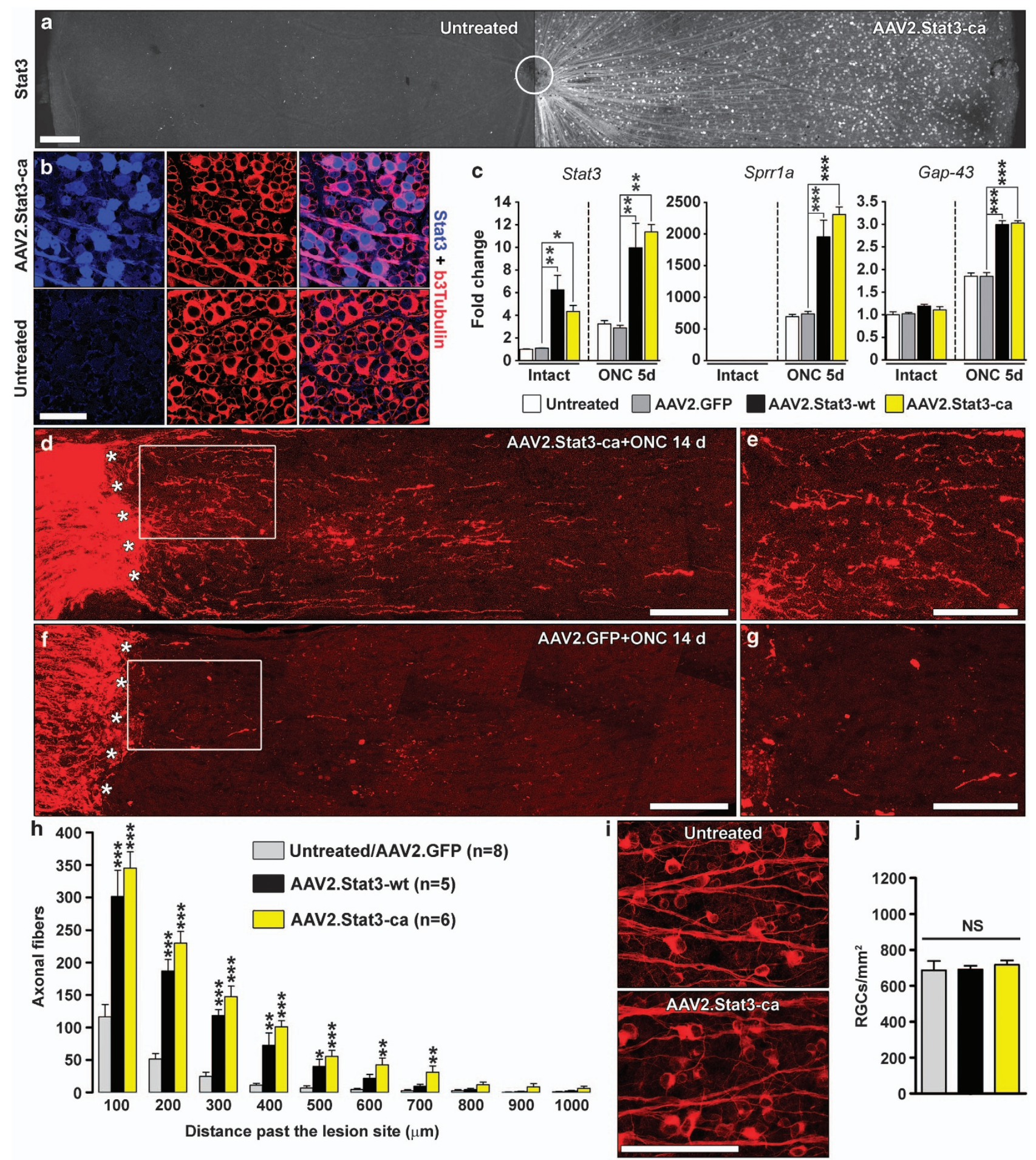

Figure 1 Retinal ganglion cell transduction with wild-type (WT) or constitutively active (ca) Stat3 is sufficient to promote axonal regeneration in the injured optic nerve. (a) Four weeks after AAV2.Stat3-ca injection into adult mouse eyes, a high density of Stat3-labeled cells was visualized using immunohistochemistry on retinal flat mounts, whereas endogenous Stat3 was undetectable in untreated contralateral retina. White circle indicated optic nerve head. (b) Double immunofluorescent staining shows that B3Tubulin-positive RGCs expressed Stat3 after AAV2.Stat3-ca infection while no endogenous Stat3 signal could be detected in untreated RGCs. (c) Using semi-qRT-PCR, Stat3 mRNA was significantly elevated by AAV2.Stat3-wt and AAV2.Stat3-ca relative to AAV2.GFP. The transcript levels of the growth-associated protein Sprr1a and GAP-43 were markedly increased by Stat3 5 days after optic nerve crush, compared with the control groups, but not in the intact retina. (d-h) Axonal regeneration was observed on optic nerve longitudinal sections at 2 weeks post lesion and after anterograde tracing with cholera toxin $\beta$ subunit coupled to alexa-594 (CTb-594). AAV2.Stat3-wt and AAV2.Stat3-ca caused more axons to grow across the injury site (white asterisks) than control AAV2.GFP virus. (e and $\mathbf{g}$ ) Magnified pictures from (d and f) reveal CTb-594labeled fibers distal to the lesion. (h) The quantification of axons at distances from 100 to $1000 \mu \mathrm{m}$ shows that AAV2.Stat3-wt and AAV2.Stat3-ca promoted more growthrespectively, up to 500 and $700 \mu \mathrm{m}$ past the lesion site than in uninjected or AAV2.GFP-injected mice. (i and j) Surviving RGCs 2 weeks after the optic nerve crush were visualized using immunohistochemistry on retinal flat-mounts. AAV2.Stat3-ca had no significant (NS) neuroprotective effect on axotomized RGCs compared with other groups. Statistics: one-way ANOVA, ${ }^{*} P<0.05$; ${ }^{* *} P<0.01 ;{ }^{* \star} P<0.001$. Scale bar: (a) $200 \mu \mathrm{m}$; (b) $=50 \mu \mathrm{m}$; (d and f) $=100 \mu \mathrm{m}$; (e and g) $=50 \mu \mathrm{m}$; (i) $=100 \mu \mathrm{m}$ 

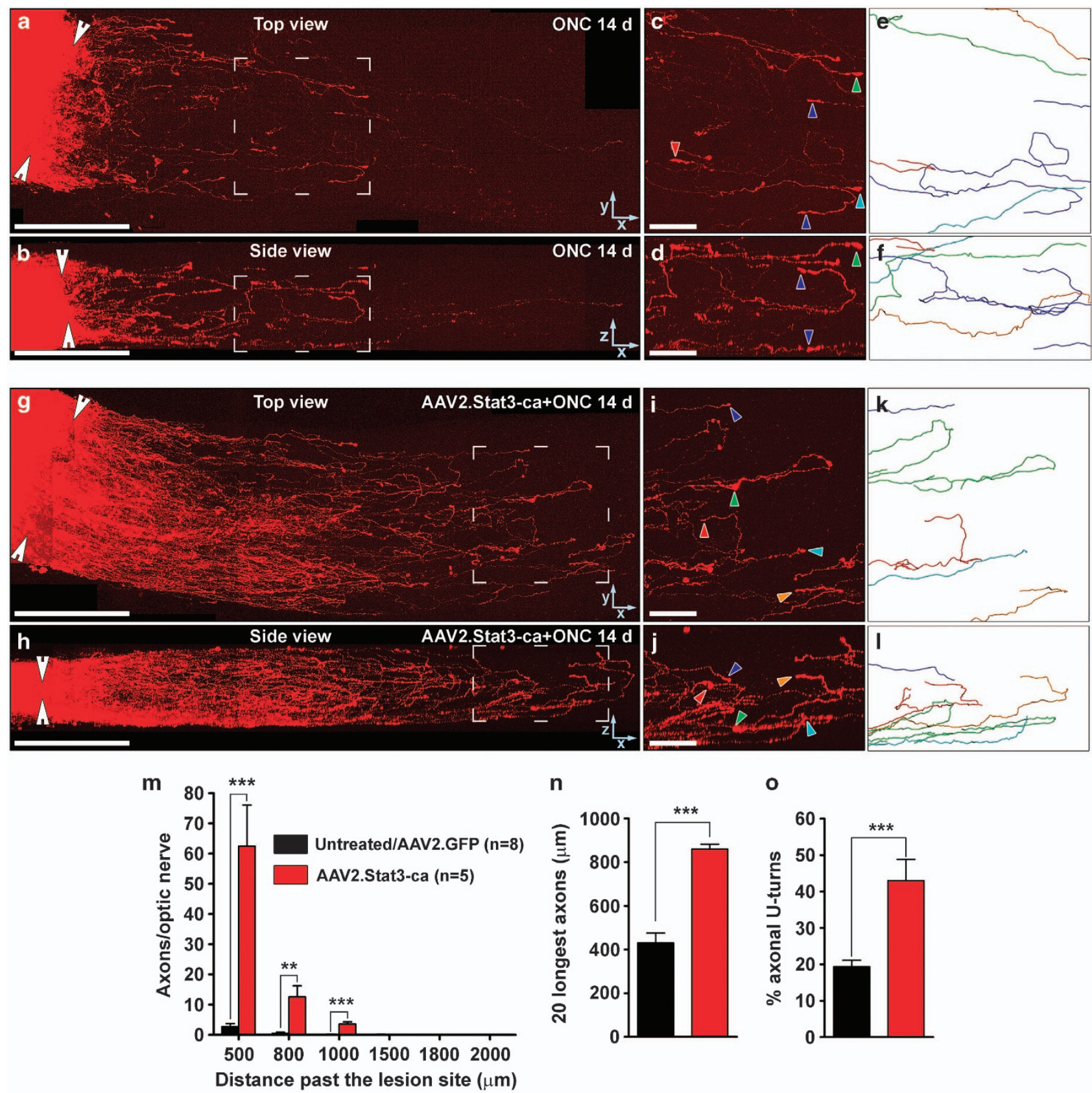

n

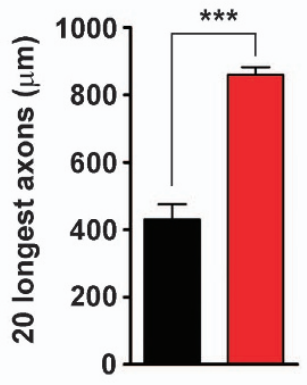

0

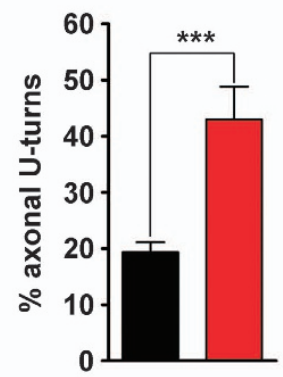

Figure 2 Three-dimensional analysis of axonal regeneration in the cleared optic nerve reveals guidance and directionality errors. Whole, unsectioned optic nerves were submitted to clearing (see methods) after CTb-594 tracing and reconstructed from serial confocal optical sections in 3D. (a-f) Top- or side-view projections of CTb-594-filled fibers illustrate the in-depth trajectories of single axons in the whole optic nerves. Two weeks after the optic nerve crush and without stimulation, the few spontaneously growing axons could be followed over $\sim 0.5 \mathrm{~mm}$, and individual axons were traced (e and f). Colored arrowheads indicate the enlarged ends of single axons (c and $\mathbf{d}$ ). Note the oblique, irregular course of the axons; some fibers show U-turns. (g-I) Stat3-ca-induced axonal regeneration was characterized by a high density of intermingled axons extending up to $>1 \mathrm{~mm}$. Fiber growth is highly irregular, and many fibers present U-turns at the regeneration front. (m) Quantitatively, AAV2.Stat3-ca stimulated significantly more axonal growth at 500, 800, and $1000 \mu \mathrm{m}$ past the lesion site than what is found in the untreated optic nerves (one-way ANOVA, $\left.{ }^{* *} P<0.01 ;{ }^{* * *} P<0.001\right)$. (n) The distance from the lesion site reached by the 20 longest axons was much longer after AAV2.Stat3-ca infection than in control conditions $\left(t\right.$-test, $\left.{ }^{* * *} P<0.001\right)$. (0) The proportion of U-turns, calculated for the 20 longest axons, was more than doubled with AAV2.Stat3-ca injection, compared with control mice left untreated or injected with AAV2.GFP (t-test, $\left.{ }^{* \star *} P<0.001\right)$. Scale bar: $(\mathbf{a}, \mathbf{b}, \mathbf{g}, \mathbf{h})=200 \mu \mathrm{m} ;(\mathbf{c}-\mathbf{f}, \mathbf{i}-\mathbf{l})=50 \mu \mathrm{m}$

Rho-kinase (ROCK) inhibition potentiates Stat3activated axonal regeneration and changes the axonal growth pattern in the optic nerve. The inhibition of axonal regeneration is mediated in large part by myelin-associated growth-inhibitory proteins that activate the intracellular
Rho-A/ROCK pathway in neurons. ${ }^{18-20}$ To block ROCK in neurons, we injected the cell-permeable inhibitor Y27632 into the vitreous space at the time of the lesion and 7 days later. Axonal regeneration was studied 2 weeks after the lesion in whole-mounted optic nerves. The intraocular delivery of 
Y27632, combined with AAV2.Stat3-ca ( $n=5$ mice), gave rise to strikingly long and straight regenerating axons (Figures 3a, b), whereas Y27632 alone ( $n=5$ mice) had no significant effect on axonal growth compared with control conditions ( $n=8$ mice; Figures $3 c, d$ ). The combination of AAV2.Stat3-ca and Y27632 increased the number of growing fibers by 2.8-, 4.7-, and 7.3-fold, respectively, 500, 800, and
$1000 \mu \mathrm{m}$ distal to the site of the injury, compared with the single injection of AAV2.Stat3-ca ( $n=5$ mice; Figures $3 e$ ). Of note, some axons extended up to $2000 \mu \mathrm{m}$ past the lesion in the group receiving the double treatment. In this group, the 20 longest axons reached a distance that was 1.6 fold as long as with AAV2.Stat3-ca injection alone (Figure 3f). A striking phenotype was also seen with regard to the
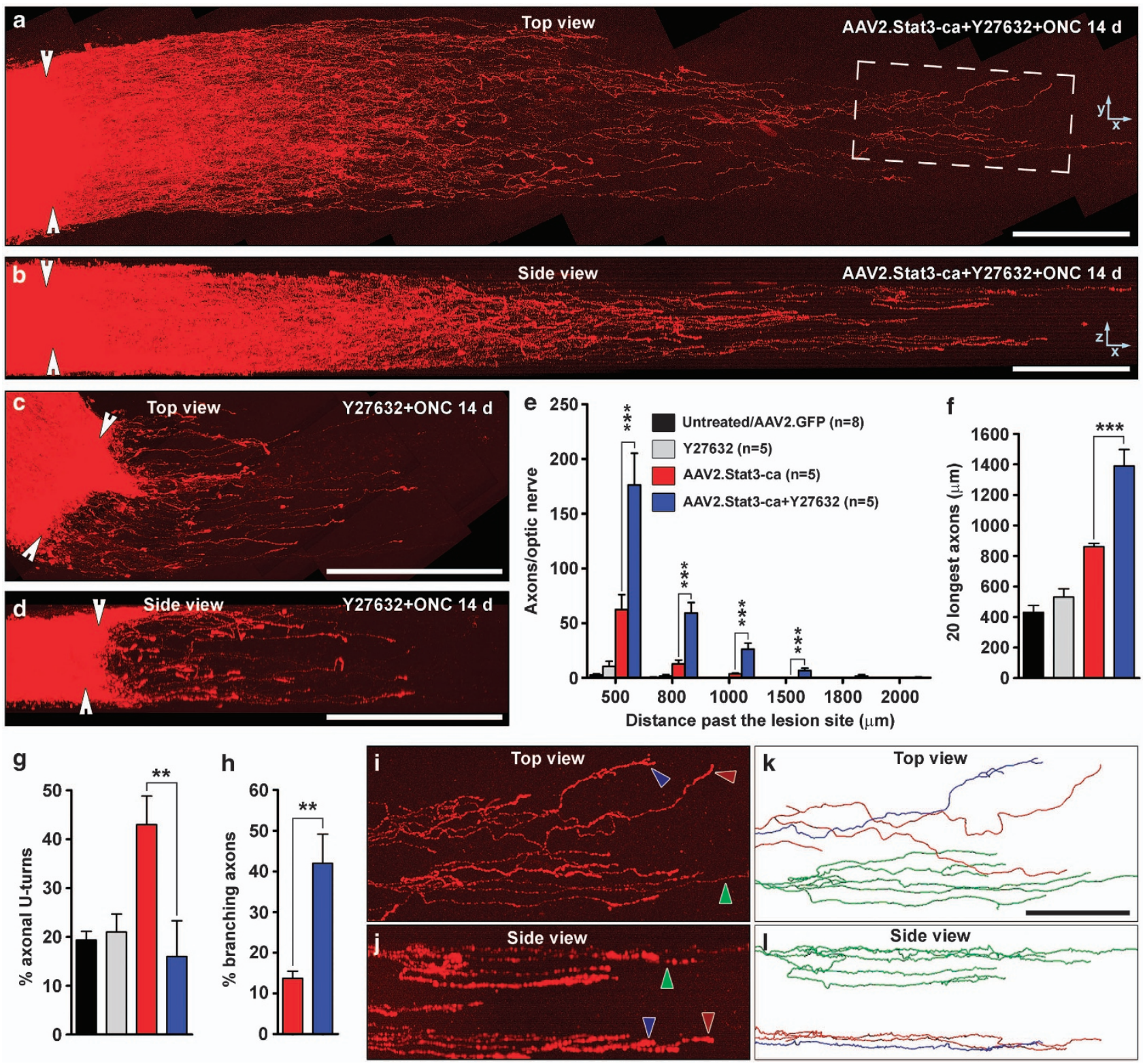

Figure 3 Rho-kinase (ROCK) inhibition potentiates Stat3-ca-induced axonal regeneration in the optic nerve and changes the pattern of fiber growth. The ROCK blocker Y27632 was administered intravitreally in adult mice treated with AAV2.Stat3-ca or in mice that were not injected with viruses. (a-d) On top-and side-view projections of whole optic nerves, the combination of AAV2.Stat3-ca and Y27632 activated the growth of strikingly long and straight axons (a and $\mathbf{b}$ ) while Y27632 by itself had no effects (c and $\mathbf{d}$ ). (e) Quantitatively, the number of axonal fibers was significantly higher with AAV2.Stat3-ca and Y27632 at 500, 800, 1000 and $1500 \mu \mathrm{m}$ past the injury site than in control animals or only Y27632-injected mice. Statistical test could not be applied at longer distances as control groups showed no fibers contrary to the combined stimulation. (f) With AAV2.Stat3-ca and Y27632, the 20 longest axons reached a distance that was 1.6 times as long as that reached by axons treated with AAV2.Stat3-ca alone. (g) The percentage of U-turns was strongly reduced by combining Y27632 and AAV2.Stat3-ca treatment. (h) The proportion of branching axons was increased threefold in optic nerves treated with AAV2.Stat3-ca and Y27632 together, compared with AAV2.Stat3-ca alone ( $t$-test, ${ }^{* *} P<0.01$ ). (i and j) High-magnification images (from a dotted rectangle) showing top- and side-view projections at the regeneration front. ( $\mathbf{k}$ and $\mathbf{I})$ Individual axons traced in different colors exhibited different degrees and pattern of branching. Statistics: (e-g): One-way ANOVA, ${ }^{\star \star} P<0.01 ;{ }^{* \star} P<0.001$. Scale bars: $(\mathbf{a}-\mathbf{d})=200 \mu \mathrm{m} ;(\mathbf{i}-\mathrm{I})=100 \mu \mathrm{m}$ 
morphology of the regenerating axons: they were straighter, deviated less from their courses along the nerve, and the frequency of axonal U-turns dropped from $43 \%$ of axons in the AAV2.Stat3-ca group to $16 \%$ of axons in the AAV2.Stat3ca/Y27632 group (Figures 3g, i-l). Interestingly, AAV2.Stat3ca, together with Y27632, also affected the branch formation of the axons: $42 \%$ of the axons distal to the lesion showed branching in the AAV2.Stat3-ca/Y27632 group, compared with $13.7 \%$ in the AAV2.Stat3-ca alone group (Figures 3h, k). We also analyzed the survival of RGCs 2 weeks after the nerve crush (Supplementary Figure S2). Combining AAV2.Stat3-ca and Y27632 protected more RGCs $(n=4$ mice; $860 \pm 40 \mathrm{RGC} / \mathrm{mm}^{2}$ ) from optic nerve-crush-induced cell death than the individual administration of AAV2.Stat3-ca $\left(n=6\right.$ mice; $\left.718 \pm 24 \mathrm{RGC} / \mathrm{mm}^{2}\right)$ or Y27632 ( $n=5$ mice; $576 \pm 19 \mathrm{RGC} / \mathrm{mm}^{2}$ ) (Supplementary Figure S2). All these results show that ROCK inhibition exerts powerful effects on the axonal regeneration activated by AAV2.Stat3-ca; however, it has no measurable effect on axonal growth and neuronal survival by itself.

The combination of AAV2.Stat3-ca and Y27632 mimics the CNTF effect on axonal regeneration. Ciliary neurotrophic factor (CNTF) has previously been shown to be the most potent neurotrophic factor for axonal regeneration in the mammalian optic nerve. ${ }^{3,10,21}$ It was proposed that CNTF required the activation of several signaling cascades like the Erk1/2, Stat3, and the Akt pathways to promote axonal growth, at least into peripheral nerve grafts placed on the optic nerve stump. ${ }^{10}$ We therefore wondered how the axonal regeneration obtained with AAV2.Stat3-ca and Y27632 compared with that observed after stimulation with CNTF. The sustained delivery of CNTF seems important, as repeated injections of recombinant CNTF peptide have a limited effect on axonal regeneration, probably due to the short half-life of the cytokine. ${ }^{3,9}$ We have recently found that selectively infecting the Müller glia with ShH10.DH-CNTF, an engineered adeno-associated virus, ${ }^{22}$ was a very effective way to deliver CNTF which strongly activates Stat3 in RGCs. ${ }^{5}$ When ShH10.DH-CNTF was injected into mouse eyes 3-4 weeks prior to the optic nerve crush ( $n=4$ mice), massive axonal regeneration was observed (Figures $4 a-c)$. Strikingly, with ShH10.DH-CNTF, the number of growing fibers did not differ significantly from that resulting from the selective and direct stimulation of the Stat3 pathway by AAV2.Stat3-ca and Y27632 ( $n=5$ mice; Figure 4e). Likewise, the average distance to the lesion covered by the 20 longest axons was also similar to the distance between the CNTF and the Stat3 groups (Figure 4f), and the frequency of axonal U-turns was also similar (Figure $4 \mathrm{~g}$ ). However, the addition of Y27632 to ShH10.DH-CNTF-injected eyes ( $n=4$ mice) elicited a significantly more robust axonal regeneration than AAV2.Stat3-ca/Y27632 or ShH10.DH-CNTF treatments (Figures $4 \mathrm{~d}$, e). Although not significantly different between the ShH10.DH-CNTF and ShH10.DH-CNTF/Y27632 groups, the decrease of axonal U-turns (Figure $4 \mathrm{~g}$ ) may have contributed to enhance the number of growing axons and long-distance regeneration (Figure 4f). Interestingly, however, axonal branching was significantly lower in the animals after treatment with ShH10.DH-CNTF (23 $\pm 1 \%)$ than after the co-treatment with AAV2.Stat3-ca and Y27632 $(42 \pm 7 \%)$ (Figure 4h). Moreover, combining Y27632 and ShH10.DH-CNTF stimulations did not affect axonal branching, compared with ShH10.DH-CNTF, suggesting that CNTF and Stat3 modulate the axonal growth pattern in a different manner (Figure 4h). Together, these data show that the effect of CNTF on the number and lengths of regenerating axons is fully mimicked by Stat3-ca expression in neurons plus ROCK blockade. The smaller number of U-turns in the Stat3-ca/Y27632 and CNTF/Y27632 groups, as compared with the CNTF-treated nerves, is consistent with a local attenuation of growth-inhibitory cues by the blockade of ROCK.

Y27632 boosts Stat3-regulated growth gene expression. In order to elucidate the molecular mechanisms through which the combination of AAV2.Stat3-ca and Y27632 improves axonal regeneration, we analyzed the level of phosphorylated Stat3, Erk1/2, and Akt in axotomized retinal lysates by Western blotting ( $n=3$ mice/group). The separate injection of Y27632 or AAV2.Stat3-ca had very weak effects on the level of P-Stat3, compared with control conditions (Figure 5a). In contrast, the addition of Y27632 upregulated $\mathrm{P}$-Stat3 in retinae treated with AAV2.Stat3-ca to a level that was comparable to that of the potent ShH10.DH-CNTF stimulation. In contrast, P-Akt and P-Erk1/2, which are both elevated severalfold by CNTF, did not change significantly between the co-treatment with Y27632/AAV2.Stat3-ca and AAV2.Stat3-ca virus injection alone (Figures 5a, b). When we compared the levels of different typical Stat3 target genes (Socs3, p21, ${ }^{23} \operatorname{Irf}^{24}$ and Sprr1a ${ }^{25}$ ), all of them were significantly upregulated by AAV2.Stat3-ca/Y27632, compared with the single injection of AAV2.Stat3-ca $(n=3-4$ mice/group). Importantly, AAV2.Stat3-ca and Y27632 brought the mRNA levels of growth-associated genes such as Sprr1a, Gap-43, and Atf3 to values similar to those measured after treatment with ShH10.DH-CNTF (Figure 5c). These data indicate that Y27632 positively modulates growth gene regulation, possibly in part by the phosphorylation of exogenous Stat3-ca protein in RGCs, and thereby potentiates the induction of the neuronal growth program after injury.

\section{Discussion}

Our results demonstrate an important role of Stat3 for the regulation of axonal growth in the adult retinal ganglion cells. When the morphology and the trajectory of regrowing axons were visualized in 3D in transparent whole-mounted nerves, very irregular trajectories of single axons and an elevated rate of axonal U-turns were observed. To test the role of myelinassociated inhibitors, many of which act via the Rho/ROCK pathway, ROCK was blocked pharmacologically. This ROCK blockade, along with the AAV2.Stat3-ca stimulation, promoted the extension of much longer and straighter axons and decreased the frequency of axonal U-turns. Unexpectedly, blocking ROCK also potentiated the Stat3-dependent transcription of genes, among which are Sprr1A and other growth-associated proteins. 


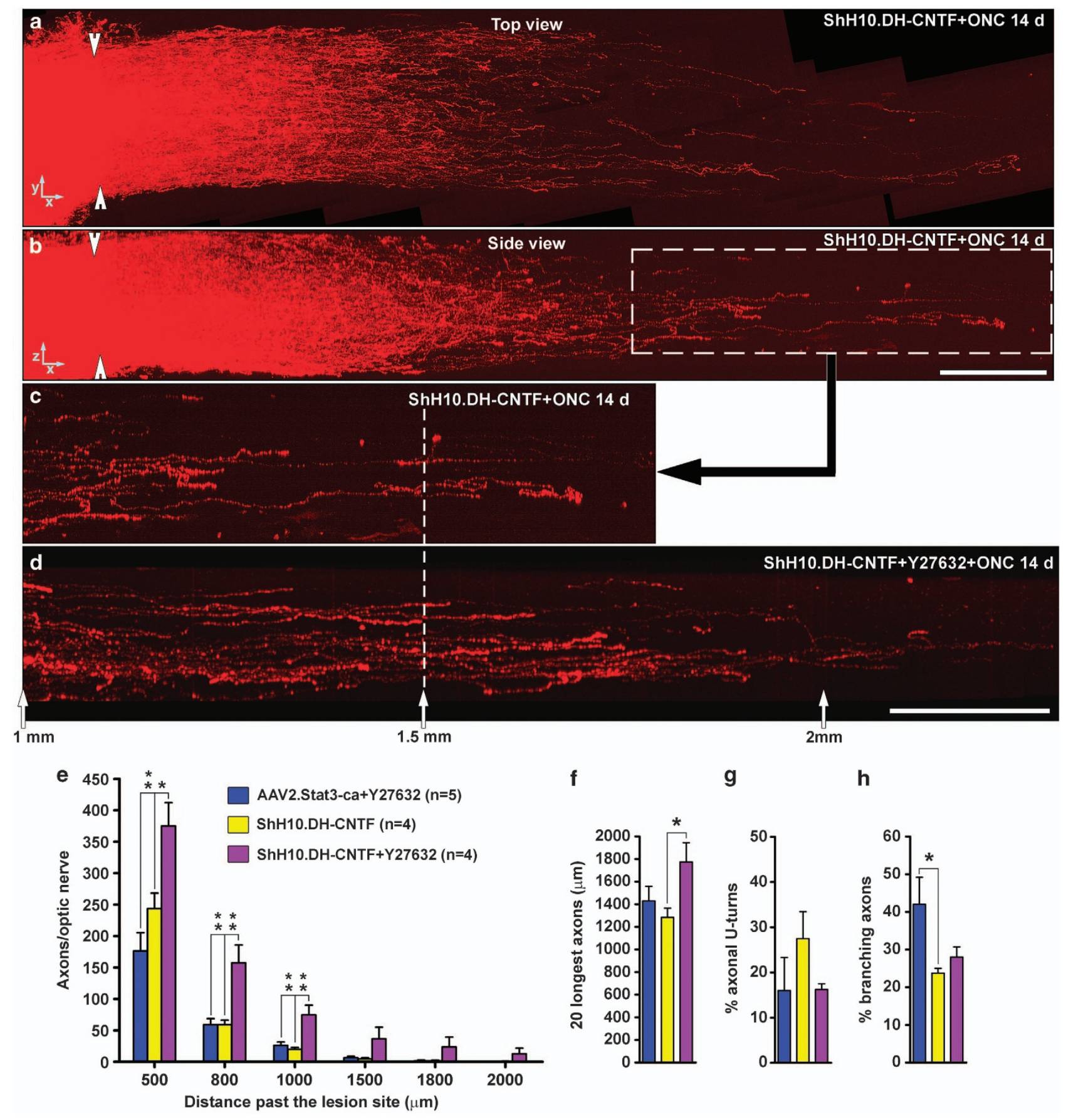

Figure 4 Combining AAV2.Stat3-ca and Y27632 promotes a similar extent of axonal regeneration as the overexpression of CNTF by Müller glia. (a and $\mathbf{b}$ ) Side-view and top-view projections of CTb-594 stained retinal axons distal to the crush site (arrow heads) in the whole-mounted optic nerve after ShH10.DH-CNTF-mediated infection of Müller glia 2 weeks after optic nerve crush. (c and $\mathbf{d})$ High-magnification pictures of distal optic nerve segments showed the improvement of long-range axonal regeneration after adding Y27632 to ShH10.DH-CNTF-injected mice. (e) Quantitatively, the number of growing fibers was not different between the groups receiving AAV2.Stat3-ca/ Y27632 and CNTF but significantly increased by combining ShH10.DH-CNTF and Y27632. (f) The longest distance from the lesion site reached by the 20 longest axons after the injury was comparable between the AAV2.Stat3-ca and ShH10.DH-CNTF groups but was enhanced in mice receiving the double ShH10.DH-CNTF/Y27632 treatment (t-test, $\left.{ }^{*} P<0.05\right)$. (g) The percentage of axonal U-turns tended to be higher in ShH10.DH-CNTF-treated mice than in the AAV2.Stat3-ca/Y27632 group. (h) In contrast, the axonal branching was significantly lower with ShH10.DH-CNTF than with AAV2.Stat3-ca/Y27632. Statistics: One-way ANOVA, ${ }^{*} P<0.05 ;{ }^{* *} P<0.01$. Scale bar: $(\mathbf{a}$ and $\mathbf{d})=200 \mu \mathrm{m}$

The growth patterns, directionality choices, and guidance phenomena of regenerating axons after optic nerve injury or other CNS tract systems have barely been studied up to now.
Using a 3D method of analysis, we could observe the behavior of single axons growing spontaneously after injury or under the influence of growth-promoting treatments in 


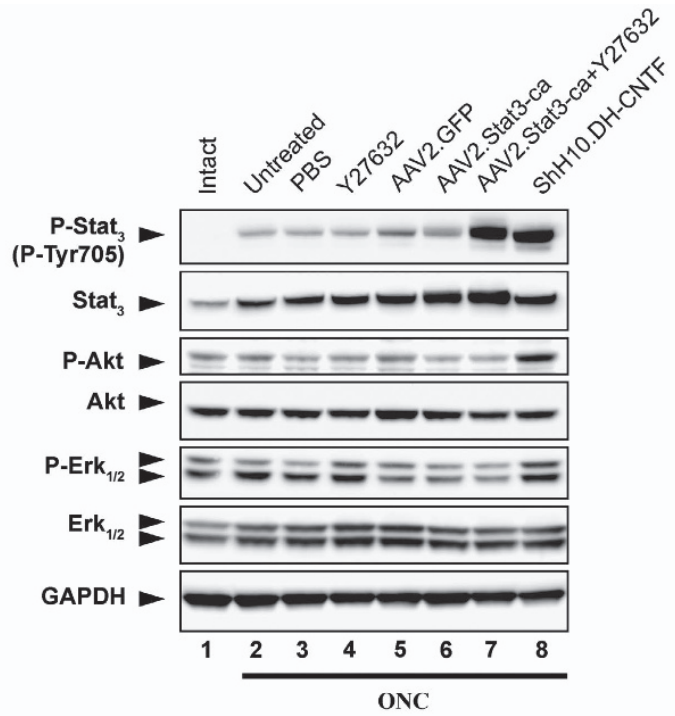

b
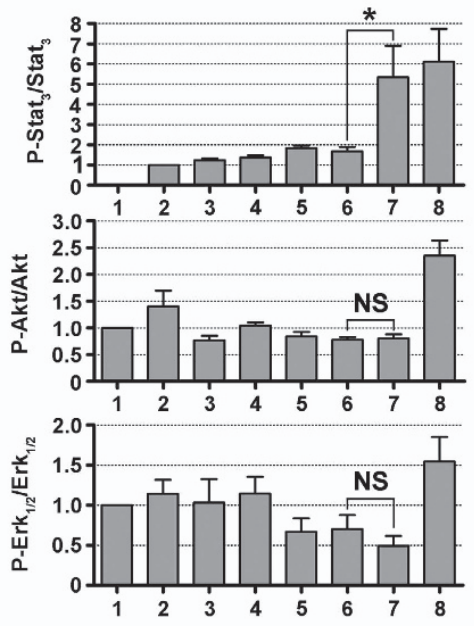

C

Socs 3

$$
p 21
$$

Iff1

Sprr1A

Gap-43
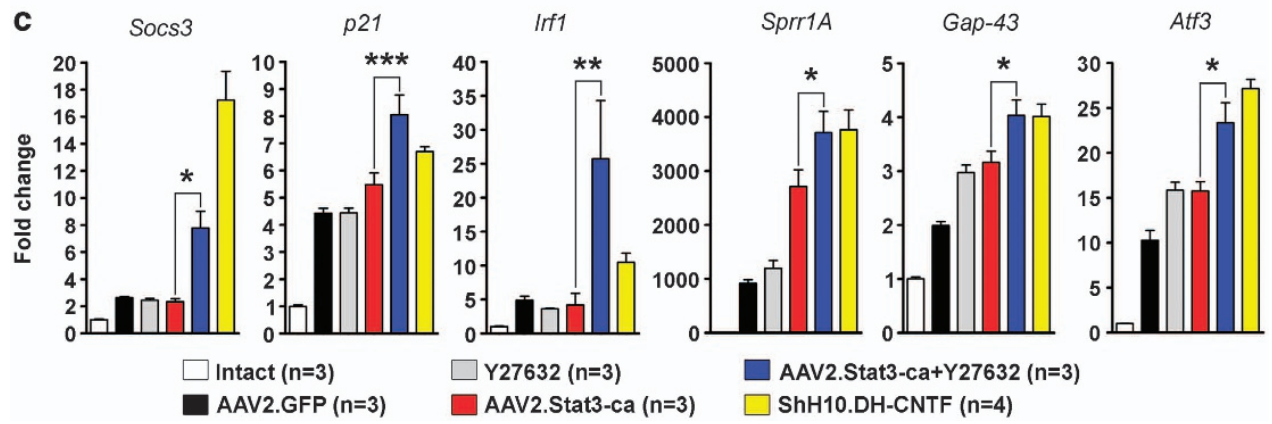

AAV2.Stat3-ca+Y27632 (n=3)

$\square$ ShH10.DH-CNTF (n=4)

Figure 5 Y27632 boosts growth gene transcription by Stat3. (a and $\mathbf{b}$ ) The activation of the Jak/Stat3, Erk1/2 and PI3K/Akt signaling cascades was monitored by western blot analysis, 5 days after the optic nerve crush. Stat3 phosphorylation was dramatically increased on Tyr705 when Y27632 and AAV2.Stat3-ca were applied together, while the two separate treatments had much weaker effects. Note that CNTF also stimulated P-Akt and P-Erk1/2 phosphorylation in addition to P-Stat3. Values in (b) were quantified by densitometry and normalized to total, unphosphorylated proteins. (c) The expression of Stat3-dependent growth-related genes was monitored by qRT-PCR in the different experimental groups. The combination of Y27632 and AAV2.Stat3-ca resulted in a higher upregulation than AAV2.Stat3-ca alone and was comparable to that obtained with CNTF for $4 / 6$ of the markers. Statistics: one-way ANOVA, ${ }^{\star} P<0.05 ;{ }^{* \star} P<0.01 ;{ }^{* \star \star} P<0.001$; NS: not significant

whole-mounted optic nerves. The 3D analysis, by itself, offered the possibility of accurately determining the number of regenerating axons, whereas the traditional assessment done on cross or longitudinal sections only considers fiber fragments that may or may not belong to the same axons. The study here described the unexpected occurrence of U-turns and branches that may have led to an overestimation of the number of regenerating axons in some stimulation conditions, using the conventional counting technique.

The careful examination of axonal morphologies revealed that the few axons extending spontaneously without any treatment shortly beyond the lesion site were mostly unbranched and occasionally formed U-turns. In this case, the main impediment to axonal growth seems to be the weak intrinsic growth capacity of adult RGC neurons. After growth stimulation with AAV2.Stat3-ca, AAV2.Stat3-ca/Y27632, or ShH10.DH-CNTF, axonal regrowth was strongly enhanced; many more fibers grew over significantly longer distances. Interestingly, the number of axonal U-turns in the AAV2.Stat3-ca- or ShH10.DH-CNTF-treated nerves was reduced, and axons appeared straighter and reached longer distances from the crush site when Y27632 was added.
On the other hand, the combination of AAV2.Stat3-ca and Y27632 induced more axonal branching. All these results are in line with a model where axonal regeneration is regulated at two levels: (i) the cell body, where intrinsic neuronal mechanisms determine the entry of the cell into a growth mode after an axonal injury has occurred, and (ii) the growing axon tip, which is exposed to cues in its environment, many of which are growth-inhibitory in the adult CNS. RGCs are known to have a particularly poor endogenous regenerative response; in agreement with this, Y27632 alone had no or a very minor effect on axonal growth beyond the lesion site (this study). ${ }^{26,27}$ The morphological characteristics of Stat3-ca-stimulated regeneration, however, show that Y27632 specifically and locally counteracted Rho-mediated repulsive effects, leading to misguidance and $\mathrm{U}$-turns. The observed increase in branch formation under these conditions is also in line with a more growth-permissive local substrate in the nerve. By contrast, the combination of ShH10.DH-CNTF and Y27632 reduced the number of axonal $\mathrm{U}$-turns without affecting the branching when compared with ShH10.DH-CNTF injection alone. Besides Stat3, the other signaling pathways activated by CNTF, such as Erk1/2, Akt, ${ }^{10}$ or NF- $k \mathrm{~B},{ }^{28}$ may have 
participated in producing long, straight, and poorly branched axons in the optic nerve. In this regard, the method described here in the visual system may be particularly useful to determine the effects of separate signaling cascades on the pattern of axonal regeneration in vivo. Importantly, these results also show that growth stimulation of the ganglion cells alone may not be sufficient to achieve successful longdistance regeneration and re-connection to the target. Indeed, the strongest growth stimulatory treatments used so far (Pten and Socs3 co-deletion, CNTF stimulation) demonstrated a sharp decline of regenerating axon numbers along the optic nerve, with only a small fraction reaching the optic chiasm and extending beyond. ${ }^{6,11,17,29}$ Additional treatments to counteract the local inhibitory effects of CNS tissue and myelin and perhaps upregulate positive-guidance molecules and attractive factors are clearly needed. Cytokines or the related neurokines (CNTF, LIF, and so on) can directly or indirectly (via inflammatory cells and astrocytes) stimulate the growth of injured neurons. ${ }^{9,21,30,31}$ Stat3 is an essential component of intracellular cytokine receptor signaling. The present results show that Stat3 is a strong inducer of the growth and regeneration program of adult RGC neurons. A different approach was previously used to activate intracellular Stat3 by deleting its upstream repressor SOCS3. ${ }^{11}$ In this condition, the effects of SOCS3 were still dependent on the cytokine receptor activation; however, we also observed that Stat3 phosphorylation induced by the combination of AAV2.Stat3ca and Y27632 or by ShH10.DH-CNTF was associated with a higher magnitude of induction of growth genes and axonal regeneration, implying that Stat3 Tyr705 phosphorylation is required to drive downstream gene activation/expression and to boost axonal regeneration. This hypothesis is in line with previous studies demonstrating that constitutively active Stat3 phosphorylation was critical for its transcriptional activity in vitro. ${ }^{32,33}$

Interestingly, we did not find significant changes in the levels of P-Erk1/2 or P-Akt after the administration of AAV2.Stat3-ca alone or in conjunction with Y27632, suggesting that the axonal regeneration obtained with AAV2.Stat3-ca/ Y27632 can be attributed mostly to the phosphorylation of Stat3 and its transcriptional activity. Consistently with this, the constitutive activation of Erk $1 / 2$ could not elicit axonal regeneration but increased $\mathrm{RGC}$ survival after optic nerve lesion. ${ }^{13}$ There was an important difference between the ShH10.DH-CNTF and AAV2.Stat3-ca/Y27632 groups: ShH10.DH-CNTF was observed to rescue $\sim 57 \%$ of $\mathrm{RGCs} / \mathrm{mm}^{2} 2$ weeks after injury, while AAV2.Stat3-ca/ Y27632 protected $\sim 24 \%$ of RGCs $/ \mathrm{mm}^{2}{ }^{5}$ The activation of Erk1/2 by CNTF may, thus, participate in the higher neuroprotective effects observed after the cytokine stimulation.

Stimulation of the neuronal growth program, in addition to enhancing neuronal survival, would be of great importance as a novel treatment of eye diseases in which ganglion cell death is prominent, like for example in glaucoma. In the CNS at large, enhancement of plasticity and regeneration would be highly desirable as one component of novel therapeutic approaches after injury. The selective stimulation of Stat3 expression in neurons would avoid potential side effects that may appear with the prolonged administration of cytokines affecting the inflammatory and immune system or inducing reactive gliosis. ${ }^{34-36}$ Moreover, the present finding that the activation of Stat3-ca can be modulated using the drug Y27632 points to a second level of control for such therapeutic interventions, which can increase the safety and feasibility.

In summary, the present 3D analysis of regenerating axons in whole-mounted adult mouse optic nerves revealed major problems with regard to pathfinding and directionality of the growing fibers that could be corrected by blocking the Rho/ROCK pathway. In turn, Stat3 was shown to be a key mediator of neurokine signaling as well as a major regulator of neurite growth and regeneration in adult retinal ganglion cells. The mutant Stat3-ca construct, the effects of which can be enhanced by $Y 27632$, could have future clinical relevance in diseases like glaucoma with progressive ganglion cell dysfunction.

\section{Materials and Methods}

Animals. Two- to four-month-old male C57BL/6 mice were used for optic nerve crush injuries and for tissue analysis. Animal experiments were conducted in agreement with the guidelines of the Veterinary Office of the Canton of Zürich.

Generation of recombinant AAV vectors. AAV vectors were produced by the plasmid co-transfection method. ${ }^{37}$ Recombinant AAV was purified via iodixanol gradient ultracentrifugation, as described previously. ${ }^{38}$ The $40 \%$ iodixanol fraction was then buffer-exchanged against phosphate-buffered saline (PBS) supplemented with $0.001 \%$ Tween and concentrated using $100 \mathrm{~K}$ Amicon Ultra-15 centrifugal filter units to a final volume of $200 \mu \mathrm{l}$. DNase-resistant viral genomes in the concentrated stock were then titered by quantitative PCR relative to standards. ${ }^{39}$ Vector concentrations were calculated in viral genomes $/ \mathrm{ml}$ with AAV2.GFP, AAV2.Stat3-wt, AAV2.Stat3-ca, and ShH10.DH-CNTF at $2-4 \times 10^{13} \mathrm{vg} / \mathrm{ml}$.

Intraocular injections. AAV vectors or the anterograde tracer cholera toxin $\beta$ subunit conjugated to alexa-594 (CTb-594, $0.5 \%$ in PBS, $1.5-2 \mu$ l, Molecular Probes, Zug, Switzerland) were injected as previously described. ${ }^{13}$ AAV $(1 \mu \mathrm{l})$ were intravitreously injected 4 weeks before optic nerve crush or tissue analysis, a duration of time that allowed optimal transgene expression in vivo. ${ }^{22,40}$ To block the activation of ROCK, $2 \mu \mathrm{l}$ of the pharmacological inhibitor Y27632 $(3 \mathrm{mM}$, in PBS) was administered intraocularly at the time of the optic nerve lesion and 1 week later (Sigma-Aldrich, Buchs, Switzerland, \#Y0503).

Neuronal survival and retinal flat-mount immunostaining. The survival of RGCs was studied 2 weeks after intraorbital optic nerve crush, at $\sim 0.25 \mathrm{~mm}$ from the eyeball. The mice were intracardially perfused with $4 \%$ paraformaldehyde (PFA) and the retinae were rapidly dissected and flat-mounted. After overnight postfixation with 4\% PFA, RGCs were labeled by immunofluorescence by applying an anti- $\beta 3$-Tubulin antibody ( $1: 500$, Abcam, Cambridge, UK, \#ab18207) diluted in PBS containing $0.3 \%$ of Triton-X-100, $5 \%$ of normal serum and $0.05 \%$ sodium azide. To follow Stat3 expression in RGCs, some retinal flatmounts were incubated with a rabbit anti-Stat3 antibody $(1: 200$, Cell Signaling, Allschwil, Switzerland, \#9132) and a mouse anti- $\beta 3$-Tubulin (1:500, Promega, Madison, WI, USA, \#G712A). After extensive washing, the retinae were incubated with corresponding secondary antibodies at $4{ }^{\circ} \mathrm{C}$. To examine neuronal survival, RGCs stained for $\beta 3$ Tubulin were imaged in the four quadrants of the retina using a Leica SPE-II confocal microscope at 40X (NA 1.25), with a step size of $0.5 \mu \mathrm{m}$ and a resolution of $1024 \times 1024$ pixels $(0.27 \mu \mathrm{m} / \mathrm{pixel})$. The number of RGC cell bodies was quantified in areas of $62500 \mu \mathrm{m}^{2}$ at $1 \mathrm{~mm}$ and $1.5 \mathrm{~mm}$ from the optic disk. The density of RGCs per $\mathrm{mm}^{2}$ was calculated in each quadrant or in the whole retina.

Axonal regeneration analysis. The optic nerve was crushed with a 9-0 suture to minimize the size of the injury as previously reported. ${ }^{14}$ Care was taken not to damage the ophthalmic artery, and the retinal blood supply was controlled after each surgery by a fundus examination. One day before fixation with paraformaldehyde $(4 \%)$, the optic axons were anterogradely traced by injecting $1.5 \mu \mathrm{l}$ of $0.5 \%$ CTb into the vitreous body. Two types of histological analyses 
Table 1 Primer sequences used for qRT-PCR

\begin{tabular}{|c|c|c|c|c|}
\hline Gene & Forward $\left(5^{\prime}-3^{\prime}\right)$ & Reverse $\left(5^{\prime}-3^{\prime}\right)$ & Annealing temp $\left({ }^{\circ} \mathbf{C}\right)$ & Product (bp) \\
\hline Atf3 & ACCTCCTGGGTCACTGGTATTTG & TTCTTTCTCGCCGCCTCCTTTTCC & 62 & 215 \\
\hline Gap-43 & TGCTGTCACTGATGCTGCT & GGCTTCGTCTACAGCGTCTT & 62 & 127 \\
\hline Gapdh & CAGCAATGCATCCTGCACC & TGGACTGTGGTCATGAGCCC & 58 & 96 \\
\hline Irf1 & CCTGGCTAGAGATGCAGAT & TCACTTCCTCGATGTCTGG & 60 & 255 \\
\hline$P 21$ & CTTGCACTCTGGTGTCTGA & GCGCTTGGAGTGATAGAA & 60 & 110 \\
\hline Pias3 & TGCAGGGACCCTTCTACAAA & GGGGTCAGCAGTCAGTTTCT & 60 & 94 \\
\hline$R p / 19$ & TGAGTATGCTCAGGCTACAG & GAATGGACAGTCACAGGCTT & 62 & 175 \\
\hline Socs 3 & ATTTCGCTTCGGGACTAGC & AACTTGCTGTGGGTGACCAT & 58 & 126 \\
\hline Sprr1a & GAACCTGCTCTTCTCTGAGT & AGCTGAGGAGGTACAGTG & 62 & 91 \\
\hline Stat3 & CAAAACCCTCAAGAGCCAAGG & TCACTCACAATGCTTCTCCGC & 62 & 139 \\
\hline
\end{tabular}

were undertaken for axonal regeneration, that is, on tissue sections or in the whole-mounted optic nerve after clearing (see below). For first type of analysis, axons labeled with CTb-594 were visualized on longitudinal sections of optic nerve (14 $\mu \mathrm{m})$ using a Zeiss Axioskop 2 Plus microscope (Carl Zeiss), and images were captured using a CCD video camera at 20x. The number of growing axons per optic nerve was evaluated at $100-1000 \mu \mathrm{m}$ past the lesion site at $100-\mu \mathrm{m}$ intervals. ${ }^{13}$ The total number of axons per optic nerve $(\Sigma)$ was estimated with the following formula: $\Sigma_{\mathrm{d}}=\Pi \times R^{2} x$ (the average number of axons $\left./ \mathrm{mm}\right) / T$. The sum $(\Sigma)$ of axons at a given distance $(d)$ was obtained using the average optic nerve radius $(R)$ of all the optic nerves, and a thickness $(T)$ of the tissue slices of $14 \mu \mathrm{m} .{ }^{41}$ For statistical analysis, an ANOVA followed by a Tukey post hoc test was applied. Animals presenting ischemia or retinal hemorrhages were excluded from the analysis.

Optic nerve clearing and 3D reconstruction. To scan CTb-594labeled axons in the whole optic nerve, the tissue was cleared following the adapted protocol of Dodt et al..$^{7}$ After a $2-h$ post-fixation in $4 \%$ PFA, the optic nerves were washed twice in PBS and then dehydrated in baths of increasing concentrations of ethanol $(50,80$, and $96 \%)$ for $1 \mathrm{~h}$ at room temperature under agitation and kept overnight in $100 \%$ ethanol. To remove the traces of water, optic nerves were then placed in $100 \%$ hexane for $2 \mathrm{~h}$ at room temperature. The clearing solution composed of the mixture of benzyl alcohol and benzylbenzoate $(1: 2)$ (Sigma-Aldrich) was then rapidly added after hexane removal. The white optic nerve turned transparent within $30 \mathrm{~s}$ to $1 \mathrm{~min}$. The whole optic nerves were mounted in a clearing medium before imaging. Image stacks were captured using a confocal Leica SP5 inverted microscope (Leica Microsystems, Mannheim, Germany) equipped with a $63 \mathrm{X}$ glycerin immersion objective (NA: 1.3). This setup was used to scan axons throughout the whole thickness of the optic nerve. To obtain 3D reconstruction of CTb-594-labeled axons in the optic nerve, image stacks were stitched using the XuvTools ${ }^{42}$ software and the resulting macro-stacks were exported to the Imaris Software (Bitplane, Zürich, Switzerland) to create 3D projections (Videos 1, 2). The number of growing axons was estimated throughout the whole thickness of the optic nerve using the ortho-slicer function allowing single plane observation. Individual axons were analyzed semi-automatically with the Filament Tracers's advanced manual tracing mode ('AutoDepth'). The percentage of U-turns and branching were calculated for the 20 longest axons. Axons presenting one or more collateral processes in the last $200 \mu \mathrm{m}$ of their course were considered as branched, irrespectively of the length of the collaterals. Snapshots of the top- and side-view projections were captured in the orthogonal mode.

Semi-quantitative real-time RT-PCR (qRT-PCR). After cervical dislocation, retinae were rapidly dissected in RNA Later solution (Ambion, Zug, Switzerland), placed in eppendorf tubes, flash frozen in liquid nitrogen, and stored at $-80^{\circ} \mathrm{C}$ until RNA was extracted. Total retinal RNA was prepared using the RNeasy RNA isolation kit (Qiagen, Hilden, Germany), including a DNase treatment to digest the residual genomic DNA. For reverse transcription, equal amounts of total RNA were transformed by oligo(dT) and M-MLV reverse transcriptase (Promega). Ten nanograms of CDNA were amplified in the Light Cycler 480 thermocycler (Roche Diagnostics AG, Rotkreuz, Switzerland) with the polymerase ready mix (SYBR Green I Master; Roche Diagnostics AG). The appropriate primer pairs were designed to span intronic sequences or to cover exon-intron boundaries (Table 1). The analysis of the melting curve for each amplified PCR product and the visualization of the PCR amplicons on $2 \%$ agarose gels allowed controlling the specificity of the amplification. Relative quantification was calculated using the comparative threshold cycle $\left(\Delta \Delta^{\mathrm{CT}}\right)$ method. cDNA levels were normalized to Gapdh or to Rpl19 (reference genes), and a control sample (calibrator set to 1) was used to calculate the relative values. For each gene, the PCR-amplification efficiency was established from the slope of the calibration curve according to the equation: $E=10^{(-1 / \text { slope) })}{ }^{43}$ Each reaction was done in triplicate, and at least three mice per condition were analyzed.

Western blot analysis. To prepare retinal lysates, three mice were killed for each condition by cervical dislocation and retinae were quickly placed in an eppendorf tube and snap frozen in liquid nitrogen. Tissues were then homogenized in a lysis buffer $\left(20 \mathrm{mM}\right.$ Tris- $\left.\mathrm{HCl}, 0.5 \% \mathrm{CHAPS} \mathrm{pH}_{8}\right)$ containing protease inhibitors (Complete mini, Roche Diagnostics AG) for $60 \mathrm{~min}$ on ice. Soluble proteins in the supernatant were collected in clean eppendorf tubes, and stored at $-80^{\circ} \mathrm{C}$ after centrifugation for $15 \mathrm{~min}$ at $15000 \times \mathrm{g}, 4^{\circ} \mathrm{C}$. Retinal proteins $(20 \mu \mathrm{g} /$ well) were resolved by electrophoresis on a $4-12 \%$ gradient polyacrylamide gel and transferred to nitrocellulose membranes. The membranes were pre-incubated in a blocking solution of $2 \%$ Top Block (Lubio Science, Lucerne, Switzerland) dissolved in TBST (Tris-base $0.1 \mathrm{M}, 0.2 \%$ Tween-20, pH 7.4) for $1 \mathrm{~h}$ at room temperature, incubated with primary antibodies overnight at $4{ }^{\circ} \mathrm{C}$ and after washing, with a horseradish peroxidase-conjugated anti-mouse or anti-rabbit antibody (1:10000-1:25000; Pierce Biotechnology). Primary antibodies were rabbit anti-phospho-Stat3 (1:500, Cell Signaling, \#9131), rabbit anti-phospho-Akt (1:1000, Cell Signaling, \#9275), rabbit anti-Akt (1:1000, Cell Signaling, \#9272), rabbit anti-phospho-Erk1/2 (1:1000, Cell Signaling, \#4370), rabbit anti-Erk1/2 (1:1000, Cell Signaling, \#4695) and mouse anti-glyceraldehyde3-phosphate dehydrogenase (GAPDH, 1:20000; abcam, \#ab8245). Protein bands were detected by adding SuperSignal West Pico Chemiluminescent Substrate (Pierce) and after exposure of the blot in a Stella detector.

\section{Conflict of Interest}

The authors declare no conflict of interest.

Acknowledgements. This work was supported by Swiss National Science Foundation (SNF) Grants nr. 31-122527 and 31-138676, the SNF National Center of Competence in Research 'Neural Plasticity and Repair', and the Velux Stiftung (project \#817). We would like to thank Franziska Christ for her technical help and Dr. Olivier Raineteau for allowing us to use his SPE-II confocal microscope. We are grateful to Dr. Florence Bareyre for kindly providing us with the AAV2.Stat3 plasmids. For 3D analysis, imaging was performed using equipment maintained by the Center for Microscopy and Image Analysis, University of Zürich (ZMB).

1. Moore DL, Blackmore MG, Hu Y, Kaestner KH, Bixby JL, Lemmon VP et al. KLF family members regulate intrinsic axon regeneration ability. Science 2009; 326: 298-301.

2. Park KK, Liu K, Hu Y, Smith PD, Wang C, Cai B et al. Promoting axon regeneration in the adult CNS by modulation of the PTEN/mTOR pathway. Science 2008; 322: 963-966.

3. Leaver SG, Cui Q, Plant GW, Arulpragasam A, Hisheh S, Verhaagen J et al. AAV-mediated expression of CNTF promotes long-term survival and regeneration of adult rat retinal ganglion cells. Gene Ther 2006; 13: 1328-1341. 
4. Leaver SG, Cui Q, Bernard O, Harvey AR. Cooperative effects of bcl-2 and AAV-mediated expression of CNTF on retinal ganglion cell survival and axonal regeneration in adult transgenic mice. Eur J Neurosci 2006; 24: 3323-3332.

5. Pernet V, Joly S, Dalkara D, Jordi N, Schwarz O, Christ F et al. Long-distance axonal regeneration induced by CNTF gene transfer is impaired by axonal misguidance in the injured adult optic nerve. Neurobiol Dis 2013; 51: 202-213.

6. De Lima S, Koriyama Y, Kurimoto T, Oliveira JT, Yin Y, Li Y et al. Full-length axon regeneration in the adult mouse optic nerve and partial recovery of simple visual behaviors. PNAS 2012; 109: 9149-9154.

7. Dodt HU, Leischner U, Schierloh A, Jahrling N, Mauch CP, Deininger $\mathrm{K}$ et al. Ultramicroscopy: three-dimensional visualization of neuronal networks in the whole mouse brain. Nat Methods 2007; 4: 331-336.

8. Erturk A, Mauch CP, Hellal F, Forstner F, Keck T, Becker $\mathrm{K}$ et al. Three-dimensional imaging of the unsectioned adult spinal cord to assess axon regeneration and glial responses after injury. Nat Med 2012; 18: 166-171.

9. Muller A, Hauk TG, Fischer D. Astrocyte-derived CNTF switches mature RGCs to a regenerative state following inflammatory stimulation. Brain 2007; 130: 3308-3320.

10. Park K, Luo JM, Hisheh S, Harvey AR, Cui Q. Cellular mechanisms associated with spontaneous and ciliary neurotrophic factor-cAMP-induced survival and axonal regeneration of adult retinal ganglion cells. J Neurosci 2004; 24: 10806-10815.

11. Smith PD, Sun F, Park KK, Cai B, Wang C, Kuwako K et al. SOCS3 deletion promotes optic nerve regeneration in vivo. Neuron 2009; 64: 617-623.

12. Bromberg JF, Wrzeszczynska MH, Devgan G, Zhao Y, Pestell RG, Albanese C et al. Stat3 as an oncogene. Cell 1999; 98: 295-303.

13. Pernet V, Hauswirth WW, Di Polo A. Extracellular signal-regulated kinase 1/2 mediates survival, but not axon regeneration, of adult injured central nervous system neurons in vivo. J Neurochem 2005; 93: 72-83.

14. Pernet V, Joly S, Dalkara D, Schwarz O, Christ F, Schaffer D et al. Neuronal Nogo-A upregulation does not contribute to ER stress-associated apoptosis but participates in the regenerative response in the axotomized adult retina. Cell Death Differ 2012; 19: 1096-1108.

15. Almasieh M, Wilson AM, Morquette B, Cueva Vargas JL, Di Polo A. The molecular basis of retinal ganglion cell death in glaucoma. Prog Retin Eye Res 2012; 31: 152-181.

16. Bonilla IE, Tanabe K, Strittmatter SM. Small proline-rich repeat protein $1 \mathrm{~A}$ is expressed by axotomized neurons and promotes axonal outgrowth. J Neurosci 2002; 22 1303-1315

17. Sun F, Park KK, Belin S, Wang D, Lu T, Chen G et al. Sustained axon regeneration induced by co-deletion of PTEN and SOCS3. Nature 2011; 480: 372-375.

18. Pernet V, Schwab ME. The role of Nogo-A in axonal plasticity, regrowth and repair Cell Tissue Res 2012; 349: 97-104.

19. Schwab ME. Functions of Nogo proteins and their receptors in the nervous system Nat Rev Neurosci 2010; 11: 799-811.

20. Nash $\mathrm{M}$, Pribiag $\mathrm{H}$, Fournier $\mathrm{AE}$, Jacobson $\mathrm{C}$. Central nervous system regeneration inhibitors and their intracellular substrates. Mol Neurobiol 2009; 40: 224-235.

21. Muller A, Hauk TG, Leibinger M, Marienfeld R, Fischer D. Exogenous CNTF stimulates axon regeneration of retinal ganglion cells partially via endogenous CNTF. Mol Cell Neurosci 2009; 41: 233-246.

22. Klimczak RR, Koerber JT, Dalkara D, Flannery JG, Schaffer DV. A novel adeno-associated viral variant for efficient and selective intravitreal transduction of rat Muller cells. PLOS One 2009; 4: e7467.

23. Coqueret $\mathrm{O}$, Gascan $\mathrm{H}$. Functional interaction of STAT3 transcription factor with the cell cycle inhibitor p21WAF1/CIP1/SDI1. J Biol Chem 2000; 275: 18794-18800.

24. Smith RP, Lerch-Haner JK, Pardinas JR, Buchser WJ, Bixby JL, Lemmon VP. Transcriptional profiling of intrinsic PNS factors in the postnatal mouse. Mol Cell Neurosci 2011; 46: 32-44.

25. Pradervand S, Yasukawa H, Muller OG, Kjekshus H, Nakamura T St, Amand TR et al. Small proline-rich protein $1 \mathrm{~A}$ is a gp130 pathway- and stress-inducible cardioprotective protein. EMBO J 2004; 23: 4517-4525.
26. Lingor P, Tonges L, Pieper N, Bermel C, Barski E, Planchamp V et al. ROCK inhibition and CNTF interact on intrinsic signalling pathways and differentially regulate survival and regeneration in retinal ganglion cells. Brain 2008; 131(Pt 1): 250-263.

27. Ahmed Z, Berry M, Logan A. ROCK inhibition promotes adult retinal ganglion cell neurite outgrowth only in the presence of growth promoting factors. Mol Cell Neurosci 2009; 42: 128-133.

28. Gallagher D, Gutierrez H, Gavalda N, O'Keeffe G, Hay R, Davies AM. Nuclear factorkappaB activation via tyrosine phosphorylation of inhibitor kappaB-alpha is crucial for ciliary neurotrophic factor-promoted neurite growth from developing neurons. J Neurosci 2007; 27: 9664-9669.

29. Park KK, Hu Y, Muhling J, Pollett MA, Dallimore EJ, Turnley AM et al. Cytokine-induced SOCS expression is inhibited by CAMP analogue: impact on regeneration in injured retina. Mol Cell Neurosci 2009; 41: 313-324.

30. Yin Y, Cui Q, Gilbert HY, Yang Y, Yang Z, Berlinicke $C$ et al. Oncomodulin links inflammation to optic nerve regeneration. Proc Natl Acad Sci USA 2009; 106 : 19587-19592

31. Leibinger M, Muller A, Andreadaki A, Hauk TG, Kirsch M, Fischer D. Neuroprotective and axon growth-promoting effects following inflammatory stimulation on mature retinal ganglion cells in mice depend on ciliary neurotrophic factor and leukemia inhibitory factor. J Neurosci 2009; 29: 14334-14341.

32. Li L, Shaw PE. Elevated activity of STAT3C due to higher DNA binding affinity of phosphotyrosine dimer rather than covalent dimer formation. J Biol Chem 2006; 281 : 33172-33181.

33. Liddle FJ, Alvarez JV, Poli V, Frank DA. Tyrosine phosphorylation is required for functional activation of disulfide-containing constitutively active STAT mutants. Biochemistry 2006; 45: 5599-5605.

34. Peterson WM, Wang Q, Tzekova R, Wiegand SJ. Ciliary neurotrophic factor and stress stimuli activate the Jak-STAT pathway in retinal neurons and glia. J Neurosci 2000; 20: 4081-4090.

35. Cen LP, Luo JM, Zhang CW, Fan YM, Song Y, So KF et al. Chemotactic effect of ciliary neurotrophic factor on macrophages in retinal ganglion cell survival and axonal regeneration. Invest Ophthalmol Vis Sci 2007; 48: 4257-4266.

36. Kirsch M, Trautmann N, Ernst M, Hofmann HD. Involvement of gp130-associated cytokine signaling in Muller cell activation following optic nerve lesion. Glia 2010; 58: 768-779.

37. Choi VW, Asokan A, Haberman RA, Samulski RJ. Production of recombinant adeno-associated viral vectors. Curr Protoc Hum Genet 2007; Chapter 12, Unit 1219.

38. Dalkara D, Kolstad KD, Caporale N, Visel M, Klimczak RR, Schaffer DV et al. Inner limiting membrane barriers to AAV-mediated retinal transduction from the vitreous. Mol Ther 2009; 17: 2096-2102.

39. Aurnhammer C, Haase M, Muether N, Hausl M, Rauschhuber C, Huber I et al. Universal real-time PCR for the detection and quantification of adeno-associated virus serotype 2-derived inverted terminal repeat sequences. Hum Gene Ther Methods 2012; 23: 18-28.

40. Cheng L, Sapieha P, Kittlerova P, Hauswirth WW, Di Polo A. TrkB gene transfer protects retinal ganglion cells from axotomy-induced death in vivo. J Neurosci 2002; 22: 3977-3986.

41. Leon S, Yin Y, Nguyen J, Irwin N, Benowitz LI. Lens injury stimulates axon regeneration in the mature rat optic nerve. J Neurosci 2000; 20: 4615-4626.

42. Emmenlauer M, Ronneberger O, Ponti A, Schwarb P, Griffa A, Filippi A et al. XuvTools: free, fast and reliable stitching of large 3D datasets. J Microsc 2009; 233: 42-60.

43. Pfaffl MW. Quantification strategies in real-time PCR. In: Bustin S (ed) $A-Z$ of Quantitative PCR. International University Line (IUL): La Jolla, CA, USA, 2004, pp 87-112.

(c) (i) $(9)$ Cell Death and Disease is an open-access journa published by Nature Publishing Group. This work is licensed under a Creative Commons Attribution-NonCommercialNoDerivs 3.0 Unported License. To view a copy of this license, visit http://creativecommons.org/licenses/by-nc-nd/3.0/

\section{Supplementary Information accompanies this paper on Cell Death and Disease website (http://www.nature.com/cddis)}

